\title{
Cosmetic uses of activated charcoal
}

\section{Muhsana Sajjad $^{1 *}$, Rida Sarwar ${ }^{2}$, Tooba Ali' ${ }^{1}$ Laiba Khan², Syed Uzair Mahmood ${ }^{3}$}

\author{
${ }^{1}$ Department of Research, Dow Medical College, Dow University of Health Sciences, Karachi, Pakistan \\ ${ }^{2}$ Department of Research, Sindh Medical College, Jinnah Sindh Medical University, Karachi, Pakistan \\ ${ }^{3}$ Department of Medicine, Health and Life Science, The Queens University of Belfast, United Kingdom
}

Received: 01 July 2021

Accepted: 10 August 2021

\section{*Correspondence: \\ Dr. Muhsana Sajjad, \\ E-mail: muhsanasajjad.ss@gmail.com}

Copyright: (C) the author(s), publisher and licensee Medip Academy. This is an open-access article distributed under the terms of the Creative Commons Attribution Non-Commercial License, which permits unrestricted non-commercial use, distribution, and reproduction in any medium, provided the original work is properly cited.

\begin{abstract}
Within the past few years, activated charcoal is being actively used in cosmetic products. Due to its adsorbing properties, it is being used in all sorts of beauty products from face masks to cleansers and even soaps. In the past, activated charcoal has been used as the treatment of poisoning but now with cosmetic companies claiming charcoal's aptness in treating skin blemishes, it has regained popularity. However, there is little to no clinical evidence to support these claims. In this study, we review the current use of activated charcoal in cosmetic products and its effectiveness. With limited research, its vigorous and unregulated use in over the counter beauty products can turn out to be unsafe. Although its use as an antidote for poisoning is evident, trials to confirm its effectiveness in treating skin conditions like acne, dark spots, dermatitis need to be prioritized to render it safe to be used in cosmetic products.
\end{abstract}

Keywords: Activated charcoal, Cosmetics, Face masks, Peel off masks, Skin care

\section{INTRODUCTION}

Activated charcoal has become a popular trend in beauty products. It is a fine black powder that is made by burning wood, coconut shells, peat and olive pits in low oxygen environment which develops pores and increases its surface area several folds up to an approximate of more than three thousand square metre per gram. ${ }^{1}$ These pores trap or absorb chemicals which enables it to draw bacteria and impurities from the skin, improve acne, treat insect bites, minimize pores, treat skin conditions. ${ }^{2,3}$

Skin is a very sensitive and protective layer of human body which is exposed to environmental pollution as well as the harmful UV rays making skin care an essential part of our lives. The facial skin is thinner and more fragile as compared to the rest of the body therefore necessitating even more care and regard from us. The cosmetic use of activated charcoal is therefore intended specifically for facial application either in the form of a cream, lotion, face mask, face wash or peel off mask. ${ }^{4}$ An appropriate facial cleanser not only has the ability to deterge our skin from potentially harmful bacteria and toxic pollutants but also boost our confidence as a consequence. ${ }^{5}$

Adsorbent properties of charcoal were described in the 1700 s, and the first clinical application occurred in the early $1800 \mathrm{~s} .{ }^{6}$ Its these adsorptive properties that have led to its use as a detox ingredient. In 2014, Gwyneth Paltrow's newsletter Goop recommended charcoal-infused lemonade as one of the year's top juice cleansers, which brought the substance to the wellness limelight. ${ }^{7}$ To today's generation, charcoal is best known for whitening teeth and removing skin blemishes. This increased admiration resulted in record breaking marketing of activated charcoal amongst all other cosmetic and beauty products. This also led to the large scale commercial production of charcoal not only in daily use soaps and handwashes but also in facial cleansers, pore strips and carbonated face masks to name a few. ${ }^{8}$ In 2015, the 
International Nomenclature of Cosmetic Ingredients (INCI) itemized 148 skincare products that had charcoal powder as an ingredient; an impressive feat for a skincare constituent as new as activated charcoal and within four years the numbers were already five times that of 2015 .

From long lost beauty myths and medical uses to the latest twentieth century skincare trends and from hesitant, skeptical consumers to becoming a high end cosmetic trend, activated charcoal has come a very long way to make its place in consumer's cosmetic preferences' and it's here to stay. ${ }^{9}$

\section{HISTORY}

The use of charcoal dates back to 3750 B.C when the Egyptians used it excessively not just to neutralize the odors of mining but also to treat various bowel problems from constipation to bloating and diarrhea. ${ }^{10}$

It was also used in the process of mummification by the Egyptians. Not only this, it was used by the ancient Greeks and Romans to maintain their oral hygiene. By 400 B.C, the civilizations settled in and around the Indus region also started to use charcoal powder for the purpose of water purification. ${ }^{11}$

Despite being in use for centuries, the first recorded scientific discovery of the adsorbent characteristic of activated charcoal dates was not until the 1700s when the scientist Lowitz observed that charcoal effectively decolorized other colors. 12

Not only this, in 1830 a French pharmacist named Tourey bravely exhibited the adsorptive quality of charcoal by ingesting a lethal dose of Strychnine, a highly toxic colorless pesticide used to kill rodents and birds, along with a substantial quantity of charcoal and remained remarkable unaffected by his risky action. ${ }^{12}$

Later on in 1834 an American physician Hort, successfully treated a patient with Mercury dichloride poisoning using powdered charcoal. ${ }^{12}$

\section{PROCESS OF COMPOSITION}

Activated charcoal is prepared from a variety of carbon containing materials like wood pulp with low ash content, lignite and rye starch. After the charcoal is obtained it is broken down into a fine granular form. After that it's activation process is started where it is treated with steam, oxygen, carbon dioxide, certain acids and other chemicals. This activating process removes all the impurities and creates fine, small granules resulting in a surface area of currently used activated charcoal of about $1000 \mathrm{~m}^{\wedge} 2$ per gram while the experimental activated charcoal has a surface area of about $3,500 \mathrm{~m}^{\wedge} 2$ per gram. ${ }^{13}$

\section{FUNCTIONAL MECHANISM}

Activated charcoal has micro pores which increase its surface area and therefore it's adsorptive properties. This enables it to trap toxins and chemicals from the skin surface, clearing away any clogged pores and detoxifying the skin surface when rinsed or peeled away. ${ }^{8}$ This action however, depends upon the chemical balance between the free toxin and activated charcoal/toxin complex.

The toxins are adsorbed in non-ionized forms because of which it is very efficient at adsorbing non polar and hydrophobic organic toxins. ${ }^{14}$

\section{USES}

Activated charcoal which has the function of adsorbing fat, dark spots and pollutants that adhere to our skin is added to skin lightening cream cosmetic preparations. ${ }^{15}$ It is also commonly used in facial cleansers, pore strips, carbonated face masks, and soaps. A number of cosmetic and pharmaceutical companies also claim that charcoal containing products can help treat adult acne, cuts, minor infections, itchy scalp, and seborrheic dermatitis. ${ }^{8}$

Some dermatologists also believe that if in the past it was used to successfully carry out the gastric lavage in patients of poison ingestion because of activated charcoal making strong bonds with the poison and ultimately flushing it out of the body, then it can also use this mechanism to bind with dead skin and bacteria attracting sebum on skin that has been exposed to environmental toxins and leave a clear and healthy skin when rinsed. ${ }^{16}$ Additionally, its antibacterial and antifungal properties can be utilized for treatment of conditions like psoriasis and eczema. ${ }^{17}$ Not only this, it also effectively removes dandruff and dirt from scalp hence making it a valuable addition to shampoos. ${ }^{18}$

Furthermore, various tooth pastes and mouth wash contain charcoal and claim to offer tooth whitening which seemingly points to its abrasive property which favors in clearing stains. ${ }^{19}$

\section{DISADVANTAGES}

Charcoal containing peel off masks can sometimes cause excessive skin peeling, particularly in people with sensitive skin or certain skin conditions resulting in a very painful situation for the consumer and is a matter of concern for many dermatologists as it can cause serious and permanent skin damage like scarring and infection. ${ }^{8}$

Not only this, charcoal containing mouthwashes have the potential to damage the aprismatic and subsurface enamel which results in severe tooth sensitivity and susceptibility to dental caries which can reverse its tooth whitening effect and instead cause tooth discoloration to tooth discoloration. ${ }^{19}$

Furthermore, there are a number of charcoal containing beauty products that are not under the jurisdiction of FDA that contain chemicals which can cause allergies and 
irritation. There have also been reported cases of chemical burns due to the presence of allergic substances which then required the treatment of topical steroids. ${ }^{8}$

Another disadvantage is that charcoal containing face masks can permanently enlarge skin pores and causing scarring and can cause permanent hypopigmentation in people with darker skin tone..$^{20}$

\section{CONCLUSION}

Even though there can in no way be any negation of the scientific experiments that have proven the highly receptive characteristic of activated charcoal that has benefitted the human race ever since its discovery yet, there is very little clinical data that can associate these absorptive qualities to its use in clinical practice in some places. However, despite its merits, while using activated charcoal for its cosmetic and dental benefits persons should also bear in mind that it is a chemical compound and precedence should be given to the fact that like any other chemical activated charcoal may react in an adverse way if not used in moderate quantities and with restraint.

Funding: No funding sources

Conflict of interest: None declared

Ethical approval: Not required

\section{REFERENCES}

1. Mcnulty B. 2019. https://lesalon.com/blog/truthcharcoal-beauty-trend/. Accessed on 01 May, 2021.

2. Higuera V. What Are the Benefits of a Charcoal Face Mask? 2019.

3. Montijo S. Is activated charcoal for skin care worth the hype. 2020.

4. Kulkarni S, Gupta AK, Bhawsar S. Formulation and Evaluation of activated charcoal peel off mask. Int J Phytopharm Res. 2018;9:40-4.

5. Kabra K, Khan I, Anamika P, Malik M, Mehrotra S, Giri S. Preparation of Face Wash Using Activated Charcoal and Green Tea Extracts. World Scientific News. 2018;113:157-63.

6. Derlet RW, Albertson TE. Activated charcoal-Past, present and future. Western Journal of Medicine. 1986;145(4):493.

7. Eschner K. The truth about activated charcoal in beauty products. 2019. https://www.popsci.co $\mathrm{m} /$ story/health/activated-charcoal-beauty-skin-care/. Accessed on 01 May, 2021.

8. Sanchez N, Fayne R, Burroway B. Charcoal: An ancient material with a new face. Clin Dermatol. 2020;38(2):262-4.
9. How Activated Charcoal Powder Became A Hot Ingredient In Skin Care. 2020.

10. The Discovery and History of Activated Carbon. https://rajahfiltertechnics.com/water-filtration /discovery-history-activated-carbon/. Accessed on 01 May, 2021.

11. The Ancient History of Toothbrushes and Toothpaste Official webpage of Colgate. 2011. https://www.colgate.com/en-us/oral-health/brush ing-and-flossing/history-of-toothbrushes-and-tooth pastes. Accessed on 01 May, 2021.

12. Andersen. AH. Experimental Studies on the Pharmacology of Activated Charcoal. Acta Pharmacologica et Toxicologica (Copenh). 1946;2(1):69-78.

13. Robert W, Derlet TEA. Activated Charcoal-Past, Present and Future. Western Journal of Medicine. 1986.

14. Silberman MG, A Taylor. StatPearls. Activated Charcoal. 2020.

15. Atmanto D, Ambarwati NSS, editors. Application of activated charcoal from coconut shell waste for the manufacture of skin lightening creams and the mechanism of the process. AIP Conference Proceedings; 2021. AIP Publishing LLC.

16. How Activated Charcoal Powder Became a Hot Ingredient in Skin Care 2020. https://www.sensientcosmetics.com/how-activated-charcoal-powder-beca me-a-hot-ingredient-in-skin-care/. Accessed on 01 May, 2021.

17. Montijo S. Is Activated Charcoal for Skin Care Worth the Hype? 2020. https://greatist.com/health/activated-charcoal-skinbenefits\#skin-benefitsIs. Accessed on 01 May, 2021.

18. Divya HK. Studies on the Addition of Activated Charcoal in Herbal Shampoo. Global Journal of Research In Engineering. 2019.

19. Brooks JK, Bashirelahi N, Hsia R-c, Reynolds MA. Charcoal-based mouthwashes: a literature review. British dental journal. 2020;228(4):290-4.

20. Little Rock A. Doctors warn of charcoal face mask dangers. 2017. https://www.wusa9.com/article/new s/local/doctors-warn-of-charcoal-face-mask-danger s/65-460532923. Accessed on 01 May, 2021.

Cite this article as: Sajjad M, Sarwar R, Ali T, Khan L, Mahmood SU. Cosmetic uses of activated charcoal. Int J Community Med Public Health 2021;8:4572-4. 